\title{
SLOWLY CHANGING BIOELECTRIC POTENTIALS ASSOCIATED WITH THE BLOOD-BRAIN BARRIER.
}

\section{J. LANGDON TAYLOR * \\ ROBERT D. TSCHIRGI}

In rabbits, rats, cats and dogs an electrical potential difference exists between the cerebral cortex and the jugular blood stream which is uniquely sensitive to alterations in $\mathrm{pH}$, whether produced by chanching inspired $\mathrm{CO}_{2}$ tension or by infusing fixed acids. Increasing arterial blood $\left[H^{+}\right]$increases cortical positivity, whereas increasing cerebrospinal fluid $\left[H^{+}\right]$decreases cortical positivity. Simultaneous measurement of cerebral cortex $\mathrm{pH}$ and arterial blood $\mathrm{pH}$ in rats has revealed the following relationship:

$$
\text { P.D. }=\mathrm{K}+33 \log _{10} \frac{[H+] \text { blood }}{[H+] \text { cortex }}
$$

where P.D. is in millivolts and $\mathrm{K}$ is a constant asymmetry potential which varies from animal to animal and arises from potential sources other than the one sensitive to $\left[H^{+}\right]$.

It is postulated that this $\left[H^{+}\right]$sensitive potential difference arises from a source of E.M.F. across the pan-vascular blood-brain barrier, and similar

* Assistant Professor of Physiology and Anatomy (University of California, Los Angeles School of Medicine). 
to a Bernstein diffusion potential, resulting from the greater permeability of the blood-brain barrier to $\left[\mathrm{H}^{+}\right]$than to anions and other cations.

Other workers have interpreted slowly changing potentials within the central nervous system as arising from the neuronal population. Although there are undoubtedly other steady potentials associated with neurons, it is difficult to explain the opposite effect of intravenous versus intrathecal $\left[\mathrm{H}^{+}\right]$by assuming a neuronal source of E.M.F. for the present studies.

Similar alterations in cerebral cortex $\mathrm{pH}$ have been observed to accompany the spreading depression of Leão, and it is postulated that the slowly changing potential accompanying this phenomenon may result from $\mathrm{pH}$ induced alterations in the trans-blood-brain barrier P.D.

Qualitatively, the trans-blood-brain barrier P.D. responds to changes in arterial and intrathecal $\left[K^{+}\right]$in the same manner as it responds to $\left[H^{+}\right]$. Other naturally occurring inorganic ions do not influence this P.D. significantly. 